\title{
The Effect of Various Dynamic, Thermodynamic and Design Parameters on the Performance of a Turbocharged Diesel Engine Operating under Transient Load Conditions
}

\author{
C.D. Rakopoulos \\ National Technical University of Athens \\ E.G. Giakoumis \\ Lion Hellas SA, Peugeot Automobiles Distr., Athens \\ D.T. Hountalas, D.C. Rakopoulos \\ National Technical University of Athens
}

Copyright ( 2004 SAE International

\begin{abstract}
Thermodynamic, dynamic and design parameters have a significant and often conflicting impact on the transient response of a compression ignition engine. Knowing the contribution of each parameter on transient operation could direct the designer to the appropriate measures for better engine performance. To this aim an explicit simulation program developed is used to study the performance of a turbocharged diesel engine operating under transient load conditions. The simulation developed, based on the filling and emptying approach, provides various innovations as follows: Detailed analysis of thermodynamic and dynamic differential equations, on a degree crank angle basis, accounting for the continuously changing nature of transient operation, analysis of transient mechanical friction, and also a detailed mathematical simulation of the fuel pump. Each equation in the model is solved separately for every cylinder of the 6-cylinder diesel engine considered. The model is validated against experimental data for various load changes.
\end{abstract}

The effect of several dynamic, thermodynamic and design parameters is studied, i.e. load schedule (type, and duration of load applied), turbocharger mass moment of inertia, exhaust manifold volume and configuration, cylinder wall temperature, aftercooler effectiveness as well as an interesting case of a malfunctioning fuel pump.

Explicit diagrams are given to show how, after an increase in load, each parameter examined affects the engine speed response, as well as other properties of the engine and turbocharger such as fuel pump rack position, boost pressure and turbocharger speed.
It is shown that certain parameters, such as the type of connected loading, the turbocharger inertia, a damaged fuel pump and the exhaust manifold volume, can have a significant effect on the engine and turbocharger transient performance. However others, such as the cylinder wall temperature, the aftercooler effectiveness and the exhaust manifold configuration have a less important effect as regards transient response and final equilibrium conditions.

\section{INTRODUCTION}

The turbocharged compression ignition engine is nowadays the most preferred prime mover in medium and medium-large units applications (electrical generation, ship propulsion, truck driving, land traction), due to its reliability and high availability combined with an excellent thermal efficiency. Nonetheless, its transient operation is often combined with off-design (e.g. turbocharger lag) and consequently non-optimum performance, pointing out the significance of proper interconnection between engine, governor, fuel pump, turbocharger and load. Towards this objective, diesel engine simulation has contributed enormously in the last twenty years.

Transient diesel engine modelling extends from quasilinear codes [1,2], where use is made of experimental data at steady-state conditions together with dynamic equations for the engine, turbocharger and governor, to more fundamental works, where the simulation is based on a detailed thermodynamic (per degree crank angle) analysis [3-8]. Here, the governor is modelled using a second order differential equation, while each cylinder in a multi-cylinder engine is assumed to behave in exactly the same way. Furthermore, the fuel pump is modelled using steady-state characteristics for the injected fuel quantity, while the combustion, heat transfer, friction and 
turbocharger modellings follow essentially the steadystate operation.

It is well understood today $[6,9,10]$ that the transient response is characterized by serious off-design and offsteady-state operations which the conventional modelling cannot predict reliably, being based on a steady-state philosophy. During the last years the research focused on transient cycles analysis [11], variable geometry turbine effects [12], pollutants emissions measurements during the transient operation $[11,13]$ and transient heat release rate analysis [14], since it is well established that the instationary operation contributes much more to the total amount of emissions than the stationary one. Moreover, software packages have been developed for complete engine cycle simulation covering also the transient response [15]. Reliable simulation via the use of multi-zone models, and measurement of the pollutants emissions during the transient operation remains an important objective.

In the present work a comprehensive transient diesel engine simulation code has been developed, which incorporates some important novel features to account for the peculiarities of the transient operation. To this aim, improved relations concerning (indirect) fuel injection, combustion, dynamic analysis, heat transfer to the cylinder walls, friction modelling, and turbocharger and aftercooler operation during the transient response have been developed, which contribute to a more indepth modelling [16-18]. Moreover, a multi-cylinder engine model is incorporated, i.e. one which solves the corresponding differential equations individually for each cylinder providing a more detailed simulation of the transient processes; the latter issue is important since during a transient event considerable differentiations in fuelling from cylinder to cylinder inside the same cycle are observed, particularly during the first cycles.

The experimental investigation was carried out on a sixcylinder, IDI, turbocharged and aftercooled, medium-high speed diesel engine of marine duty coupled to a hydraulic brake, located at the authors' laboratory. A high-speed data acquisition system was set up for measuring engine and turbocharger variables performance under both steady-state and transient operation. An extended series of experiments was conducted, with engine operations covering both speed and load changes operating schedules [18]. The engine in hand possesses a high moment of inertia which leads to slow recovery with small speed droop (difference between initial and final engine speed) and extremely low soot emissions under any load-change. The transient behaviour of the engine was predicted adequately by the developed code in spite of the long non-linear brake loading times and the indirect injection nature of the engine.

The effect of various dynamic, thermodynamic and design parameters is studied, i.e. duration of applied load-change, type of loading (resistance) connected to the engine, turbocharger mass moment of inertia, exhaust manifold volume and configuration (single or twin entry turbine), cylinder wall temperature (low heat rejection engine), aftercooler effectiveness, as well as an interesting case where a damage in the fuel pump results in delayed injection for one cylinder of the engine in hand.

Explicit diagrams are given to show how, after a ramp increase in load, each of the above mentioned parameters examined affects the engine speed response, as well as other important properties of the engine and turbocharger such as fuel pump rack position, boost pressure, turbocharger speed, load torque etc.

\section{SIMULATION ANALYSIS}

THERMODYNAMIC ANALYSIS - In the following paragraphs the main equations for the engine, fuel pump and turbocharger operation will be discussed.

General process description - There is a spatial uniformity of pressure, temperature and composition in the combustion chamber at each instant of time (singlezone model). The fuel is dodecane $\left(\mathrm{C}_{12} \mathrm{H}_{26}\right)$ with a lower heating value of $42,500 \mathrm{~kJ} / \mathrm{kg}$. Perfect gas behavior is assumed. Polynomial expressions from Ref. [19] are used for each of the four species $\left(\mathrm{O}_{2}, \mathrm{~N}_{2}, \mathrm{CO}_{2}\right.$, and $\left.\mathrm{H}_{2} \mathrm{O}\right)$ considered, concerning the evaluation of internal energy and specific heat capacities for first-law application to the engine cylinder contents [16-23].

Combustion Model - For the study of the combustion process the model proposed by Whitehouse and Way $[24,6,19]$ is used for both the main chamber and the prechamber. In this model the combustion process consists of two parts; a preparation limited combustion rate and a reaction limited combustion rate. The corresponding equations are:

$$
P=K_{1} M_{i}^{1-x} M_{u}^{x} p_{O}^{y}
$$

for the preparation rate ( $\mathrm{kg}$ of fuel per ${ }^{\circ} \mathrm{CA}$ ), which controls the burned fuel for the larger part of combustion, while for the reaction rate $(\mathrm{kg}$ of fuel per ${ }^{\circ} \mathrm{CA}$ ) which is responsible for the early part of combustion it holds:

$$
R=\frac{K_{2} p_{O}}{N \sqrt{T}} e^{-a c t / T} \int(P-R) d \varphi
$$

$M_{i}=\int\left(d m_{f i} / d \varphi\right) d \varphi$ is the total mass $(k g)$ of injected fuel up to the crank angle $\varphi$ considered, and $\left(\mathrm{dm}_{\mathrm{fi}} / \mathrm{d} \varphi\right)$ is the injection rate found from the analytical fuel injection model described later. $M_{u}=M_{i}-\int P d \varphi$ is the total mass $(\mathrm{kg})$ of unprepared fuel, 'act' is the reduced activation energy $(\mathrm{K})$ accounting for the ignition delay and $\mathrm{p}_{\mathrm{O}}$ is the partial 
pressure of oxygen (bar) in the main chamber or the prechamber.

It is vital for a proper simulation of transient response that the combustion modelling takes into consideration the continuously changing nature of operating conditions. Thus the constant $\mathrm{K}_{1}$, in the (dominant) preparation rate equation, is correlated with the Sauter mean diameter (SMD) of the fuel droplets by a formula of the type $\mathrm{K}_{1} \propto(1 / \mathrm{SMD})^{2}$ [19]. For the evaluation of SMD $(\mu \mathrm{m})$ the empirical expression proposed by Hiroyasu et al. [25] is used:

$$
\mathrm{SMD}=25.1(\Delta \mathrm{p})^{-0.135} \rho_{\mathrm{g}}^{0.12} \mathrm{~V}_{\mathrm{tot}}^{0.131}
$$

where $\Delta p$ is the mean pressure drop across the injection nozzle in MPa (derived by the fuel pump submodel), $\rho_{\mathrm{g}}$ is the density of air in $\mathrm{kg} / \mathrm{m}^{3}$ at the time the injection starts, and $V_{\text {tot }}$ is the amount of fuel delivered per cycle in $\mathrm{mm}^{3}$ per pump stroke.

Heat loss to the cylinder walls - The model of Annand is used to simulate the heat loss to the cylinder walls for both the main chamber and the prechamber $[26,19,20]$. A simple model has also been used to update the wall temperature at each consecutive cycle as a result of the increase in load (and thus fuelling). For this purpose an equation with an "hysterysis" (time lag due to inertia) factor is developed:

$$
T_{w}=T_{w_{0}}+\Delta T_{w}\left(1-e^{-d_{t} t}\right)
$$

where $d_{t}$ is a coefficient deciding how fast the wall temperature responds to the changes in fuelling, $T_{\text {wo }}$ is the initial wall temperature, and $\Delta T_{w}=\left(T_{\text {wst }}-T_{\text {wo }}\right)$ with $T_{\text {wst }}$ the instantaneous steady-state wall temperature according to the current fuelling.

Friction modelling - For the calculation of friction inside the cylinder the method proposed by Rezeka and Henein $[27,18,28]$ is adopted, which describes the non-steady profile of friction torque during each cycle. In this method the total amount of friction is divided into six parts; three of these parts are concerned with the cylinder movement, as follows:

$$
\mathrm{T}_{\mathrm{fr} 1}=\mathrm{c}_{1}\left[\mu\left(r \omega \mathrm{R}_{1}\right)\left(\mathrm{p}_{\mathrm{r}}+\mathrm{p}_{\mathrm{g}}\right) \mathrm{w}\right]^{0.5} \mathrm{D}\left(\mathrm{n}_{\mathrm{o}}+0.4 \mathrm{n}_{\mathrm{c}}\right) \mathrm{r}\left|\mathrm{R}_{1}\right|
$$

for the ring viscous lubrication,

$$
T_{\text {fr2 }}=c_{2} \pi D n_{c} w\left(p_{r}+p_{g}\right)(1-|\sin \varphi|) r\left|R_{1}\right|
$$

for the ring mixed lubrication, and

$$
\mathrm{T}_{\mathrm{fr} 3}=\mathrm{c}_{3}\left(\mu \frac{\mathrm{r} \omega \mathrm{R}_{1}}{\mathrm{~h}}\right) \mathrm{DMr} \mathrm{R}_{1}
$$

for the piston skirt losses.
The remaining three parts are concerned with the crankshaft, as follows:

$$
\mathrm{T}_{\mathrm{fr} 4}=\mathrm{c}_{4} \mathrm{n}_{\mathrm{v}} \mathrm{N}_{\mathrm{s}} \mathrm{r}\left|\mathrm{R}_{1}\right| \omega^{-0.5}
$$

for the valve train,

$$
\mathrm{T}_{\mathrm{fr} 5}=\mathrm{c}_{5} \mu \omega
$$

for the auxiliaries, and

$$
\mathrm{T}_{\mathrm{fr} 6}=\mathrm{c}_{6} \frac{\pi \mathrm{D}^{2}}{4} \mathrm{r}_{\mathrm{jb}} \mathrm{p}_{\mathrm{g}}|\cos \varphi| \omega^{-0.5}
$$

for the loaded bearings.

In the above relations, the quantity

$$
\mathrm{R}_{1}=\mathrm{C}_{\mathrm{p}} / \mathrm{r} \omega=\sin \varphi+\lambda \sin \varphi \cos \varphi / \sqrt{1-\lambda^{2} \sin ^{2} \varphi}
$$

is the instantaneous reduced piston speed [17]. Also, $n_{c}$ and $n_{0}$ are the number of compression and oil rings, respectively, $w$ the ring width $\left(w_{c}\right.$ for the compression rings and $w_{0}$ for the oil rings), $p_{r}$ the elastic pressure of the rings, $p_{g}$ the instantaneous main chamber gas pressure found from the energy analysis, $M$ the length of the piston skirt, $n_{v}$ the number of valves, $N_{s}$ the valve spring force, $r_{j b}$ the radius of the journal bearing, $h$ the thickness of the lubricating-oil film between piston skirt and cylinder liner, and finally $\mu$ the oil dynamic viscosity.

Total friction toque at each degree crank angle is the sum of the above six terms, i.e.

$$
T_{\mathrm{fr}}(\varphi)=\sum_{\mathrm{i}=1}^{6} \mathrm{~T}_{\mathrm{fr}_{\mathrm{i}}}(\varphi)
$$

The coefficients $c_{1}$ to $c_{6}$ in Equations (5) are derived through calibration with experimental data at steady-state conditions.

According to Winterbone and Tennant [10], rapid changes in loading lead to instantaneous, though considerable, deflections of the crankshaft due to great accelerations, resulting in an increase of transient mechanical friction. The following correlation is thus developed [16-18] for the transient case:

$$
\mathrm{T}_{\mathrm{fr}}(\varphi)_{\text {trans }}=\mathrm{T}_{\mathrm{fr}}(\varphi)\left[1+\mathrm{C}_{\mathrm{fr}} \frac{\varepsilon(\varphi)}{\varepsilon_{\max }}\right]
$$

where the instantaneous value for the total friction torque $\mathrm{T}_{\mathrm{fr}}(\varphi)$ from Equation (7) is corrected according to the current crankshaft angular acceleration $\varepsilon(\varphi)$ [17], thus providing the «real» transient friction torque $T_{\text {fr }}(\varphi)_{\text {trans }}$ in Equation (8). In the above equation, $\varepsilon_{\max }$ is the hypothetical maximum crankshaft deceleration 
experienced after applying a $0-100 \%$ load-change in one cycle. Obviously, its use makes the constant $\mathrm{c}_{\mathrm{fr}}$ dimensionless. Table 1 provides all the data and constants necessary for the application of the friction modelling for the particular engine.

Table 1. Data for the application of the Rezeka-Henein friction model for engine MWM TbRHS 518S.

\begin{tabular}{|l|}
\hline$-\mathrm{c}_{\mathrm{i}}(\mathrm{i}=1-6): 25 / 0.197 / 0.03 / 1.768 / 2.149 / 0.08$ \\
\hline - Number of oil/compression rings, $\mathrm{n}_{\mathrm{o}}: 2 / \mathrm{n}_{\mathrm{c}}: 3$, \\
\hline - Oil/compression ring width, $\mathrm{w}_{\mathrm{o}}: 6 \mathrm{~mm} / \mathrm{w}_{\mathrm{c}}: 3.5 \mathrm{~mm}$ \\
\hline - Length of piston skirt, $\mathrm{M}: 152.1 \mathrm{~mm}$, \\
\hline - Journal bearing radius, $\mathrm{r}_{\mathrm{jb}}: 57.5 \mathrm{~mm}$, \\
\hline - Thickness of oil film, $\mathrm{h}: 0.0018 \mathrm{~mm}$, \\
\hline - Valve spring force, $\mathrm{N}_{\mathrm{s}}: 300 \mathrm{~N}$, \\
\hline - Ring elastic pressure, $\mathrm{p}_{\mathrm{r}}: 20,000 \mathrm{~N} / \mathrm{m}^{2}$, \\
\hline - Oil dynamic viscosity, $\mu: 0.015 \mathrm{~kg} / \mathrm{m} \mathrm{s}$, \\
\hline - Number of valves per cylinder, $\mathrm{n}_{\mathrm{v}}: 2$, \\
\hline - Crank radius, $\mathrm{r}: 90 \mathrm{~mm}$, \\
\hline - Increase during transient operation (Eq. (8)) $\mathrm{c}_{\mathrm{fr}}: 0.5$ \\
\hline
\end{tabular}

Multi-cylinder model - For the proper simulation of the transient engine performance, a multi-cylinder engine model is developed, i.e. one in which all the governing differential and algebraic equations are solved individually for every one cylinder of the 6-cylinder engine under study. At steady-state operation the performance of each cylinder is essentially the same, due to the steady-state operation of the governor clutch resulting in the same amount of fuel being injected per cycle.

At transient operation, on the contrary, each cylinder experiences different fuellings during the same engine cycle due to the continuous movement of the fuel pump rack, initiated by the load or speed change. These differentiations in fuelling are sometimes in the order of $10 \%$ or even more, in the same cycle, when comparing the first and the last cylinder with respect to the firing order. Thus, they can result in significant differentiations in torque response and finally speed, so affecting significantly the whole engine operation. Figure 1 depicts the differences in two properties (quantity of injected fuel and maximum main chamber pressure) for the first and the last in firing order cylinders of the engine in hand and for the nominal load-change of 10 to $75 \%$, commencing from an initial speed of $1180 \mathrm{rpm}$. Although, as will be discussed in detail later, the engine in hand possesses a very large moment of inertia which leads to slow movement of the fuel pump rack, the differences between the performances of the two examined cylinders for every cycle of the transient event are obvious.

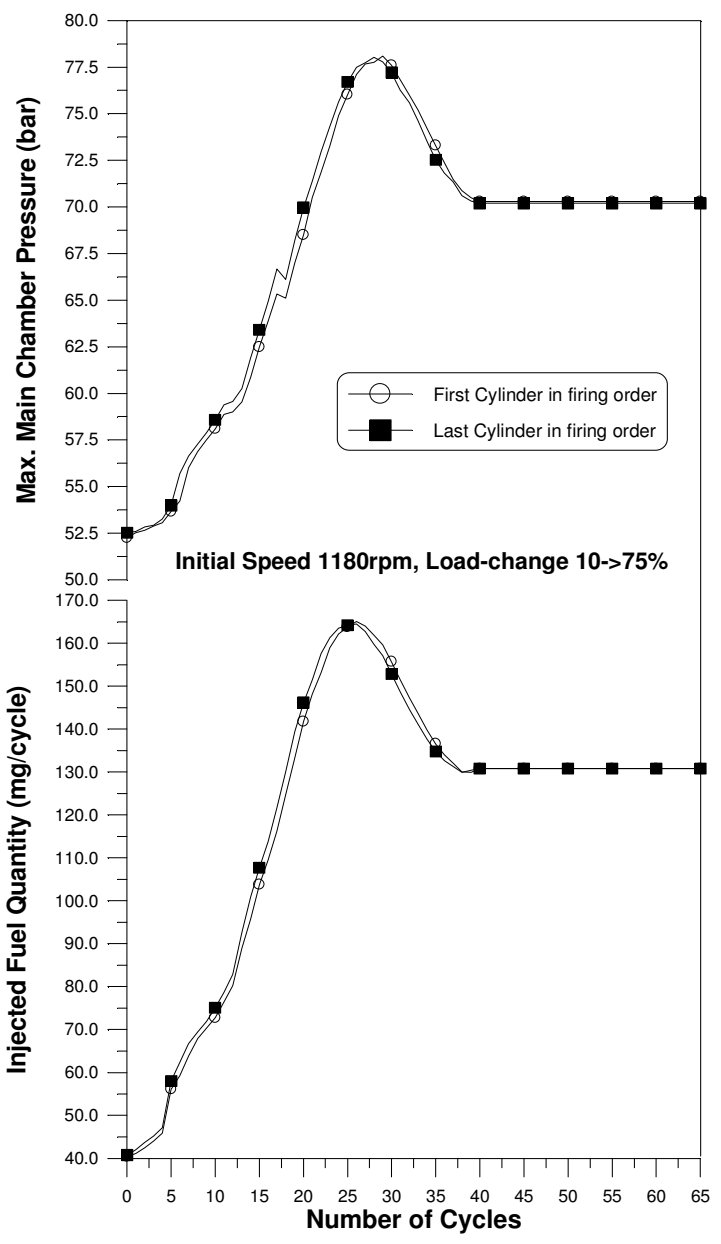

Figure 1. Comparison in the performance between first and last in firing order cylinders after an increase in load.

Fuel pump operation - The amount of fuel injected per cycle and cylinder is found according to the instantaneous values of engine speed and fuel pump rack position, existing at the point of static injection timing of the particular cylinder. In all the previous transient simulations use was made of steady-state fuel pump characteristics (rack position according to speed and load). In this work a mathematical fuel injection model is used to simulate the fuel pump, providing also the dynamic injection timing and the duration of injection for each transient cycle [29]. This constitutes a vital improvement in transient modelling, since the fuelling characteristics during a transient event differ broadly from the steady-state curves.

Turbocharger and aftercooler operation - The simulation of the turbocharger (T/C) is accomplished using the manufacturer's data at steady-state conditions. For the 
instantaneous charge air temperature $\mathrm{T}_{\mathrm{ac}}$ after the aftercooler $(\mathrm{a} / \mathrm{c})$ an "hysterysis" equation is applied,

$$
\mathrm{T}_{\mathrm{ac}}=\mathrm{T}_{\mathrm{ac}}^{\circ}+\left(\mathrm{T}_{\mathrm{ac}}^{\mathrm{st}}-\mathrm{T}_{\mathrm{ac}}^{\mathrm{o}}\right)\left(1-\mathrm{e}^{-\mathrm{c}_{\mathrm{ac}}^{\mathrm{t}}}\right)
$$

where $\mathrm{T}_{\mathrm{ac}}^{\circ}$ is the initial charge air temperature at the beginning of the transient response, $T_{a c}^{s t}=f\left(\varepsilon_{a c}\right)$ the corresponding charge air steady-state temperature according to the current aftercooler effectiveness $\varepsilon_{\mathrm{ac}}$,

$$
\mathrm{T}_{\mathrm{ac}}^{\mathrm{st}}=\left(1-\varepsilon_{\mathrm{ac}}\right) \mathrm{T}_{2}+\varepsilon_{\mathrm{ac}} \mathrm{T}_{\mathrm{cw}}
$$

with $\mathrm{T}_{2}$ the charge air temperature at the compressor outlet, $\mathrm{T}_{\mathrm{cw}}$ the cooling water temperature, and $\mathrm{c}_{\mathrm{ac}} \mathrm{a}$ constant incorporating the aftercooler thermal inertia. The $\varepsilon_{a c}$ for the present engine was found to be best correlated with the brake mean effective pressure (bmep), due to the fact of increasing cooling water flow rates with increasing engine load; a second order correlation was adopted, i.e.

$$
\varepsilon_{\mathrm{ac}}=\mathrm{b}_{1}+\mathrm{b}_{2}(\mathrm{bmep})+\mathrm{b}_{3}(\mathrm{bmep})^{2}
$$

\section{DYNAMIC ANALYSIS}

Engine dynamics - If $G_{\text {tot }}$ represents the total system moment of inertia (engine, flywheel and load), then the conservation of energy principle applied to the total system (engine plus load) yields [20,3,16-18]:

$$
T_{e}(\varphi, \omega)-T_{L}(\omega)-T_{f r}(\varphi, \omega)_{\text {trans }}=G_{\text {tot }} \frac{d \omega}{d t}
$$

where $T_{e}(\varphi, \omega)$ stands for the instantaneous value of the engine torque, consisting of the gas and the inertia forces torque. In the analysis, the complex (reciprocating and rotating at the same time) movement of the connecting rod has been taken into consideration [17]. Also,

$$
\mathrm{T}_{\mathrm{L}}(\omega)=\mathrm{k} \omega^{\mathrm{s}}
$$

is the load torque, where, for the hydraulic brake coupled to the engine examined, $s=2$. Lastly, $\mathrm{T}_{\mathrm{fr}}(\varphi, \omega)_{\text {trans }}$ stands for the friction torque during transient operation given by Equation (8).

Turbocharger dynamics - Accordingly, the dynamic equation for the turbocharger is $[30,3,18]$ :

$$
\eta_{\mathrm{mTC}} \dot{\mathrm{W}}_{\mathrm{T}}-\left|\dot{\mathrm{W}}_{\mathrm{C}}\right|=\mathrm{G}_{\mathrm{TC}} \frac{\mathrm{d} \omega_{\mathrm{TC}}}{\mathrm{dt}}
$$

where $\dot{W}_{C}$ and $\dot{W}_{T}$ are the instantaneous values for the compressor and turbine power, respectively, while the turbocharger mechanical efficiency $\eta_{\mathrm{mTC}}$ is mainly a function of its speed. The compressor and turbine operating points, for every computational step in the engine simulation code, are evaluated with the use of manufacturer's data at steady-state conditions.

Governor dynamics - To find the instantaneous fuel pump rack position $\mathrm{z}$ which is initiated by the mechanical governor clutch movement, during the transient operation, a second order differential equation is used $[3,6,18]$ :

$$
\frac{d^{2} z}{d \varphi^{2}}=a_{1} \frac{d z}{d \varphi}+a_{2} z+a_{3} z \omega^{2}+a_{4} \omega^{2}+a_{5}
$$

with constants $a_{i}(i=1-5)$ derived after calibration against experimental data under transient conditions.

COMPUTATIONAL PROCEDURE - All the equations of the above analyzed simulation are solved for every $1 / 4^{\circ} \mathrm{CA}$ for the closed part of each cycle, or every $1 / 2{ }^{\circ} \mathrm{CA}$ for the open part, separately for each cylinder. The dynamic ones are solved once every degree crank angle for the diesel engine cylinders to find the instantaneous values for engine speed $\mathrm{N}$ and crankshaft acceleration $\varepsilon$, and every $120^{\circ} \mathrm{CA}$ for the turbocharger.

\section{EXPERIMENTAL FACILITIES AND MEASUREMENTS}

The objective of the experimental test bed developed was to validate the transient performance of the engine simulation. To accomplish this task the engine was coupled to a hydraulic brake (dynamometer). Strategic measuring points were connected to a computer data logging system for recording and processing engine and turbocharger variables. The basic data for the engine, turbocharger, brake and data processing system are shown in Table 2.

The experimental investigation was conducted on an MWM TbRHS 518S, 6-cylinder, turbocharged and aftercooled, indirect injection (IDI), medium-high speed diesel engine of marine duty. The engine is fitted with a Kuehnle, Kopp \& Kausch (KKK) turbocharger and a water aftercooler after the turbocharger compressor. It is fitted with a variable-speed mechanical governor. The engine is permanently coupled to a Schenck hydraulic dynamometer. This is a variable fill brake, with the loading accomplished via the brake lever which controls the amount of water swirling inside the machine. Details about the experimental setup can be found in Ref. [18].

The first requirement from the engine test bed instrumentation was to investigate the steady-state performance of the examined engine. For this purpose, an extended series of steady-state trials was conducted in order on the one hand to examine the model's predictive capabilities and on the other to calibrate successfully the individual submodels. By so doing, the constants for the combustion, heat transfer, friction, 
aftercooler and turbocharger simulation was made possible to be estimated. The indirect injection type of the engine was of particular challenge for the simulation but the model achieved very good matching to the experimental steady-state results proving the reliability of the single-zone modelling [18].

Table 2. Basic data for engine, turbocharger, dynamometer and data logging system.

\begin{tabular}{|c|c|}
\hline $\begin{array}{l}\text { Engine Model } \\
\text { and Type }\end{array}$ & $\begin{array}{l}\text { MWM TbRHS 518S, In-line, 6-cylinder } \\
\text { 4-stroke, compression ignition, IDI, } \\
\text { turbocharged, a/cooled, marine duty }\end{array}$ \\
\hline Speed Range & $1000-1500 \mathrm{rpm}$ \\
\hline Bore/Stroke & $140 \mathrm{~mm} / 180 \mathrm{~mm}$ \\
\hline Compr. Ratio & 17.7 \\
\hline Max. Power & 320 HP (236 kW) @ 1500 rpm \\
\hline Max.Torque & 1520 Nm @ 1250 rpm \\
\hline $\begin{array}{l}\text { Intake Valve } \\
\text { Open./Closure }\end{array}$ & $51^{\circ} \mathrm{CA}$ before TDC $/ 60^{\circ} \mathrm{CA}$ after BDC \\
\hline $\begin{array}{c}\text { Exh. Valve } \\
\text { Open./Closure }\end{array}$ & $64^{\circ} \mathrm{CA}$ before $\mathrm{BDC} / 47^{\circ} \mathrm{CA}$ after TDC \\
\hline Fuel Pump & $\begin{array}{l}\text { Bosch PE-P series, in-line, 6-cylinder } \\
\text { with mechanical governor Bosch } \\
\text { RSUV } 300 / 900\end{array}$ \\
\hline Brake & Schenck U1-40, hydraulic brake \\
\hline $\begin{array}{c}\text { Total Moment } \\
\text { of Inertia }\end{array}$ & $15.60 \mathrm{~kg} \mathrm{~m}^{2}$ \\
\hline $\begin{array}{l}\text { Turbocharger } \\
\text { Model \& Type }\end{array}$ & $\begin{array}{l}\text { KKK M4B 754/345, Single-stage, } \\
\text { centrifugal compressor, Single-stage, } \\
\text { twin entry, axial turbine }\end{array}$ \\
\hline $\begin{array}{l}\text { T/C Moment } \\
\text { of Inertia }\end{array}$ & $7.5 \times 10^{-4} \mathrm{~kg} \mathrm{~m}^{2}$ \\
\hline $\begin{array}{l}\text { Data Logging } \\
\text { System }\end{array}$ & $\begin{array}{l}\text { Two 12-bit, 8-channel ADCs, } 100 \mathrm{kHz} \\
\text { max. sampling rate, installed on IBM } \\
\text { PCs }\end{array}$ \\
\hline
\end{tabular}

The investigation of transient operation was the next task. Since the particular engine is one with a relatively small speed range, mainly load changes (increases), with constant governor setting were examined. For the transient tests conducted the initial speed was 1180 or $1380 \mathrm{rpm}$ and the initial load $10 \%$ of the engine full load. The final conditions for the transient events varied from 47 to $95 \%$ of the engine full load as analyzed in detail in Ref. [18]. Prior to this, the constants for the governor movement differential Equation (13) were computed, according to the transient data collected.

\section{RESULTS AND DISCUSSION}

Two typical examples of conducted transient experiments are given in Figures 2 and 3 . Here, the initial load was $10 \%$ of the full engine load at $1180 \mathrm{rpm}$. The final load applied was almost $50 \%$ of the full engine load (Figure 2), which corresponds to a brake load increase of $400 \%$, and $75 \%$ of the full engine load (Figure 3 ), which corresponds to a brake load increase of $650 \%$; in both cases the load change was applied in 0.2 seconds.

The application of the final load was effected by the movement of the brake control lever (this task lasted 0.2 seconds), which in turn increased the amount of water inside the brake by appropriately increasing the active surface of the inlet tube. However, this hydraulic brake is characterized by a high mass moment of inertia, in the order of $5.375 \mathrm{~kg} \mathrm{~m}^{2}$, resulting in long, abrupt and non-linear actual load-change profile. The increased duration of the load application was accounted for in the simulation model by increasing the "real" load application time to $1.3 \mathrm{sec}$. The non-linear character of the load application, which could not be accounted for in the simulation, is responsible for the difference observed between experimental and simulated results during the early cycles of Figures 2 and 3 and is more obvious in Figure 3 where the load increase is greater. On the other hand, the matching between experimental and predicted transient responses is satisfactory for both engine and turbocharger variables (engine speed, maximum pressure for main chamber, fuel pump rack position and boost pressure) as regards the final conditions. More experimental-simulated results are given in Ref. [18] covering the whole speed and load range of the engine in hand as regards both steady-state and transient operation.

In the following diagrams the effect of various dynamic, thermodynamic and design parameters on the engine and turbocharger transient response will be investigated. For all cases analysed below, unless otherwise stated, the following assumptions are valid:

1. The initial load is $10 \%$ of the engine's full load at the initial speed of $1180 \mathrm{rpm}$.

2. A $650 \%$ (roughly equal to a $10-75 \%$ ) loadchange is applied in $1.3 \mathrm{sec}$ (real load application time).

3. The loading type is quadratic (hydraulic brake, $\mathrm{S}=2$ in Equation (11)).

4. The temperature of the cylinder walls ranges from $400 \mathrm{~K}$ (at the initial operating point of $10 \%$ load) to $500 \mathrm{~K}$ according to the current fuelling conditions as described by Equation (4). This temperature is assumed to remain steady during each cycle differentiating from cycle to cycle. 


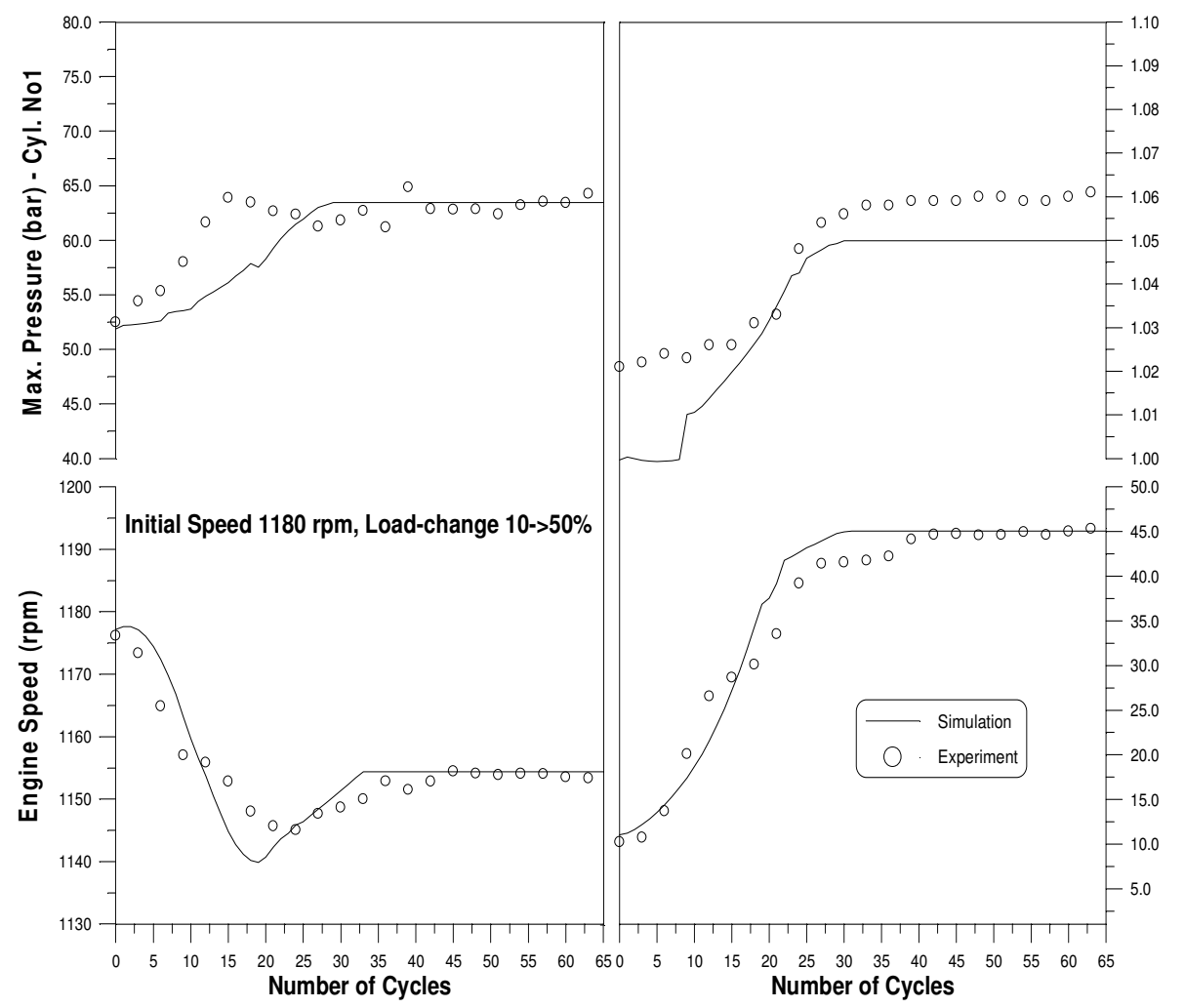

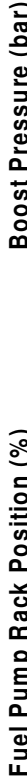

Figure 2. Experimental and predicted transient response for a $10-50 \%$ increase in load.

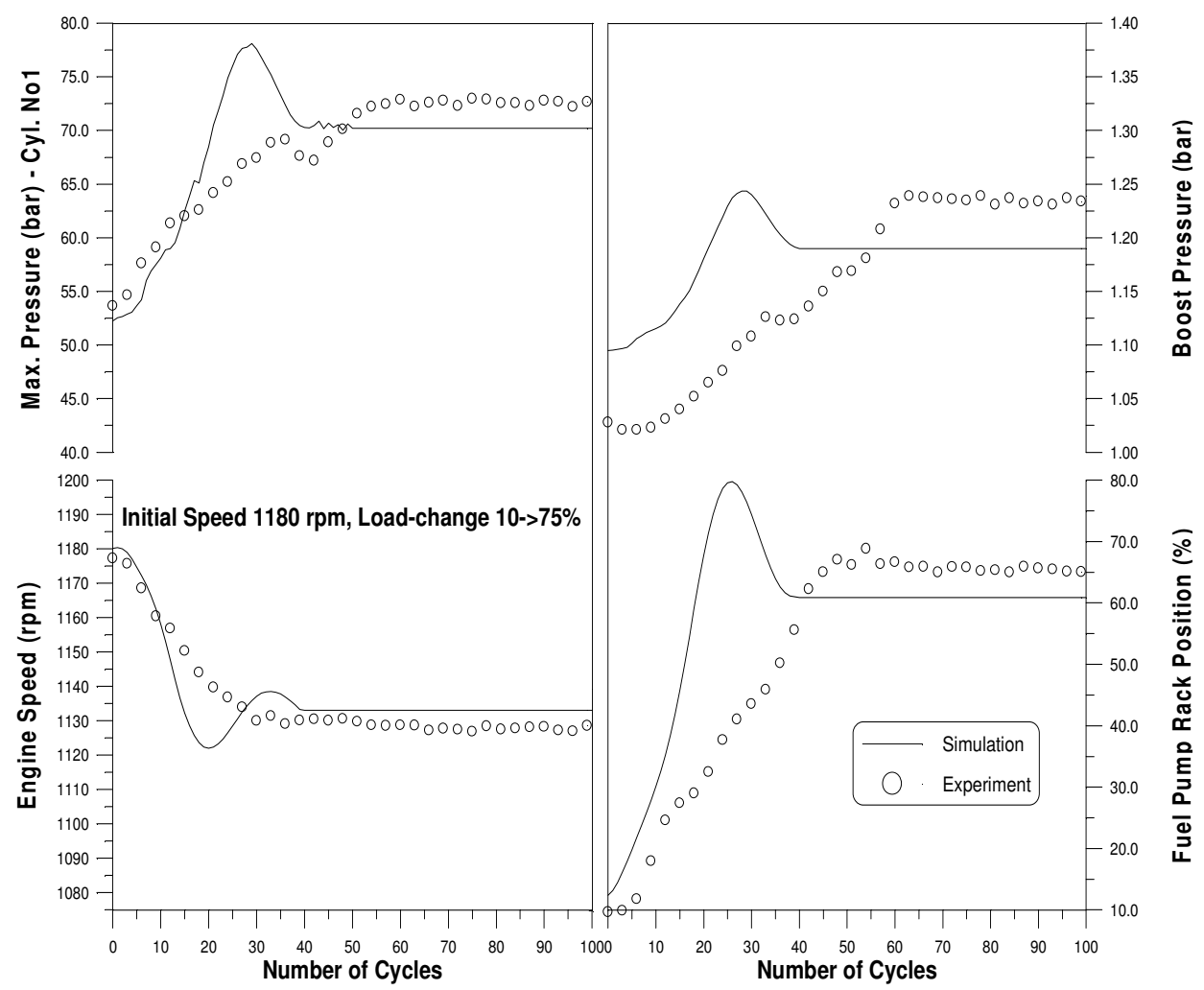

Figure 3. Experimental and predicted transient response for a $10-75 \%$ increase in load. 
Quadruple diagrams will be used to highlight each parameter's effect. In all diagrams the engine speed, the fuel pump rack position and the boost pressure responses will be given. The fourth sub-diagram will depict a different property each time; one closely related to the examined parameter (for example turbocharger speed response when the effect of turbocharger mass moment of inertia is examined).

Figure 4 presents the effect of the type of the loading connected to the engine. Here, apart from the nominal case of the quadratic loading (water brake), the rigid loading ( $s=0$ in Equation (11)) and linear loading $(s=1)$ are also examined. The load torque was chosen as the interesting property for depiction in Figure 4 together with the engine speed, fuel pump rack position and boost pressure. For those types of loading which are affected by the engine speed, the final equilibrium is reached faster and with lower speed droop (difference between initial and final engine speed). The rigid loading, on the other hand, is a more difficult case, since the response of the system depends on the engine alone. Nonetheless, since the engine in hand possesses a large moment of inertia and the applied load-change of $650 \%$ is definitely within the engine's "capability", the differences observed between the three examined resistance types is not great as regards all the depicted properties. For this reason a fourth case is also investigated in Figure 4. Here, a 900\% load-change is applied for the rigid loading case. The fuel pump rack reaches its $100 \%$ position after almost 17 cycles (roughly 1.7 seconds) and remains there unchanged, but it cannot prevent the engine from stalling since the load torque is bigger than the maximum torque the engine can produce at these speeds.

Figure 5 is focused on the effect of the duration of the applied load-change, i.e. 0, 1.3 (nominal) and 3 sec. The interesting property chosen here for depiction is the reduced angular acceleration of the engine crankshaft (see also Equation (8)). It is obvious that the fast application of load increases the initial crankshaft angular deceleration considerably, thus affecting the whole speed profile and the cycle at which the minimum speed is observed $\left(10^{\text {th }}\right.$ cycle for the instantaneous load application compared to the $35^{\text {th }}$ cycle for the " $3 \mathrm{sec}$ " case). Although the examined load-time schedules cover a large spectrum, the final engine speed droop remains only slightly affected by the particular dynamic parameter whereas the maximum speed droop is greatly influenced. The $0 \mathrm{sec}$ load application case leads also to a pulsating recovery (with decreasing magnitude) which is in general not acceptable.

Figure 6 investigates the effect of the turbocharger mass moment of inertia on the response of the engine. Two cases are examined apart from the nominal one. In the first case the T/C inertia is one fifth of the nominal inertia and in the second one its value is 10 times the nominal one. The turbocharger speed was chosen here as the fourth interesting property. The greater the turbocharger mass moment of inertia, the slower the response of the turbocharger as it is clearly depicted in the boost pressure and the turbocharger speed sub-diagrams. Thus, the response of the engine through the engine's own great mass moment of inertia does not allow significant differences between the three examined cases to be revealed. It should be noted also that the case with the very small turbocharger inertia leads to a pulsating engine response with decreasing magnitude which is unacceptable.

Figure 7 focuses on the interesting case where the static injection timing is delayed for cylinder No 3 of the engine due to some malfunctioning of the fuel pump. The brake specific fuel consumption (bsfc) was chosen here as the characteristic property. Two cases are examined: In the first one the static injection timing is $180^{\circ} \mathrm{CA}$ after BDC (bottom dead center) and in the second $200{ }^{\circ} \mathrm{CA}$ after $\mathrm{BDC}$ for the third cylinder of the engine in hand (in the nominal case the static injection timing is $154{ }^{\circ} \mathrm{CA}$ after $\mathrm{BDC})$. The delayed injection reduces considerably the efficiency of the third cylinder where, as revealed from the bsfc sub-diagram, in the early cycles of the $200{ }^{\circ} \mathrm{CA}$ case the third cylinder is motored by the other 5 cylinders, thus retarding the whole speed response of the engine. Consequently, the fuel pump rack is forced to reach more extreme positions drifting the boost pressure too. It is important to note that even though only one of the six cylinders suffers a delayed injection, this was enough for a notable increase in the engine speed droop compared to the nominal case.

Figure 8 investigates the effect of the cylinder wall temperature in the speed response of the engine. In the first case the cylinder wall temperature is $400 \mathrm{~K}$ assumed to remain steady throughout the transient event. In the second case (nominal) the wall temperature varies from 400 to $500 \mathrm{~K}$ according to the engine (steady-state) fuelling, as described by Equation (4) with the value of $\mathrm{d}_{\mathrm{t}}=0.46$, and in the third case the cylinder wall is assumed to remain steady but now at $600 \mathrm{~K}$; the latter resembles the "adiabatic" or low heat rejection case. It is made obvious from the speed responses given in Figure 8 that the cylinder wall temperature profile does not influence the speed response of the engine, although it would be very interesting to investigate its thermodynamic side-effects (mainly from the second-law perspective). Since there is not enough time available during the small duration of the transient event for the wall temperature to reach its new steady-state equilibrium dictated by Equation (4), we observe that the speed responses of cases $1\left(T_{w}\right.$ assumed steady at $400 \mathrm{~K}$ ) and 2 ( $T_{w}$ ranging from 400 to $500 \mathrm{~K}$ according to steady-state fuelling) almost coincide; a fact which is more obvious until cycle 15 (approximately $1.5 \mathrm{sec}$ after the commencement of the transient event). 


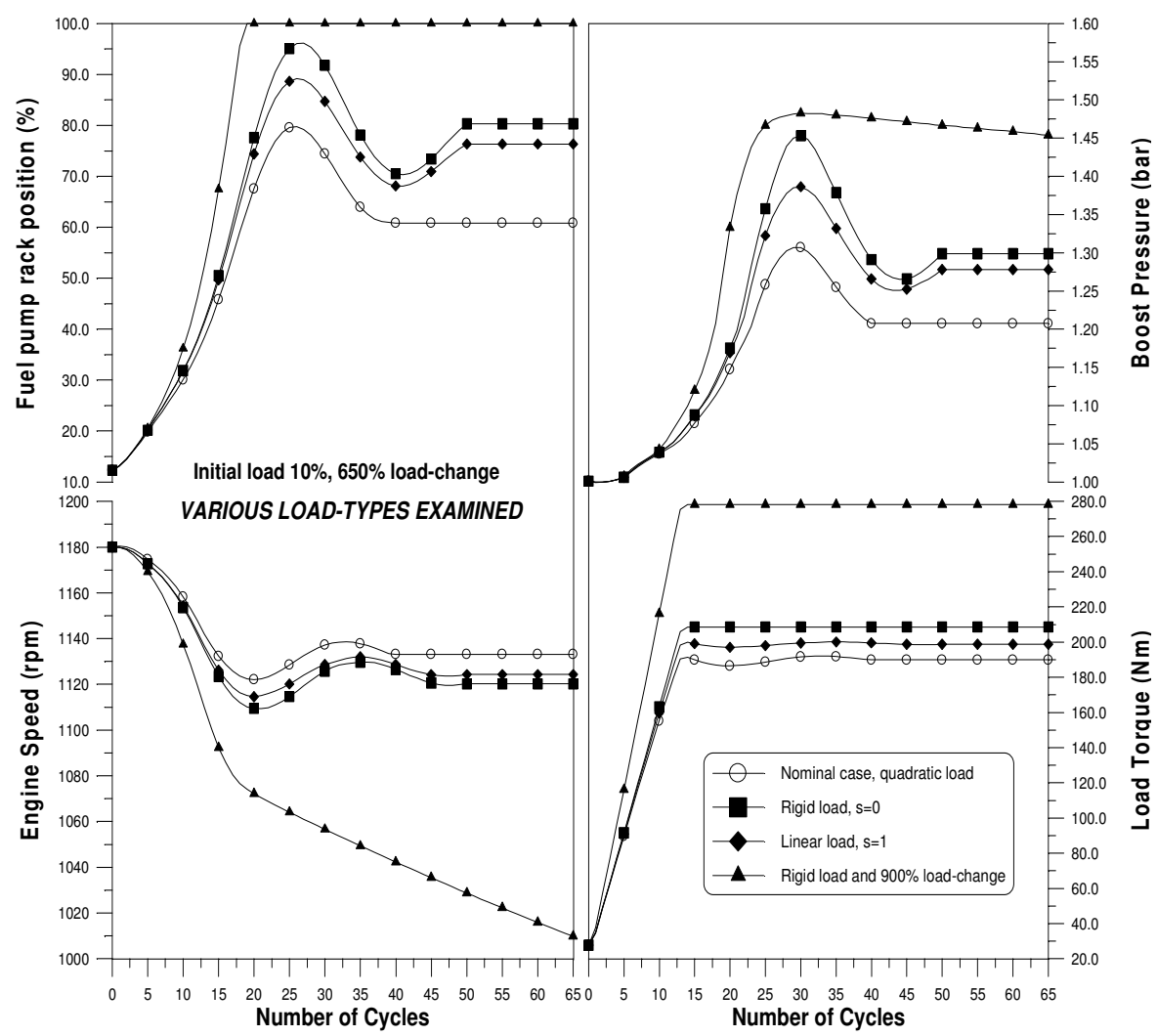

Figure 4. The effect of loading (resistance) type on the transient response.

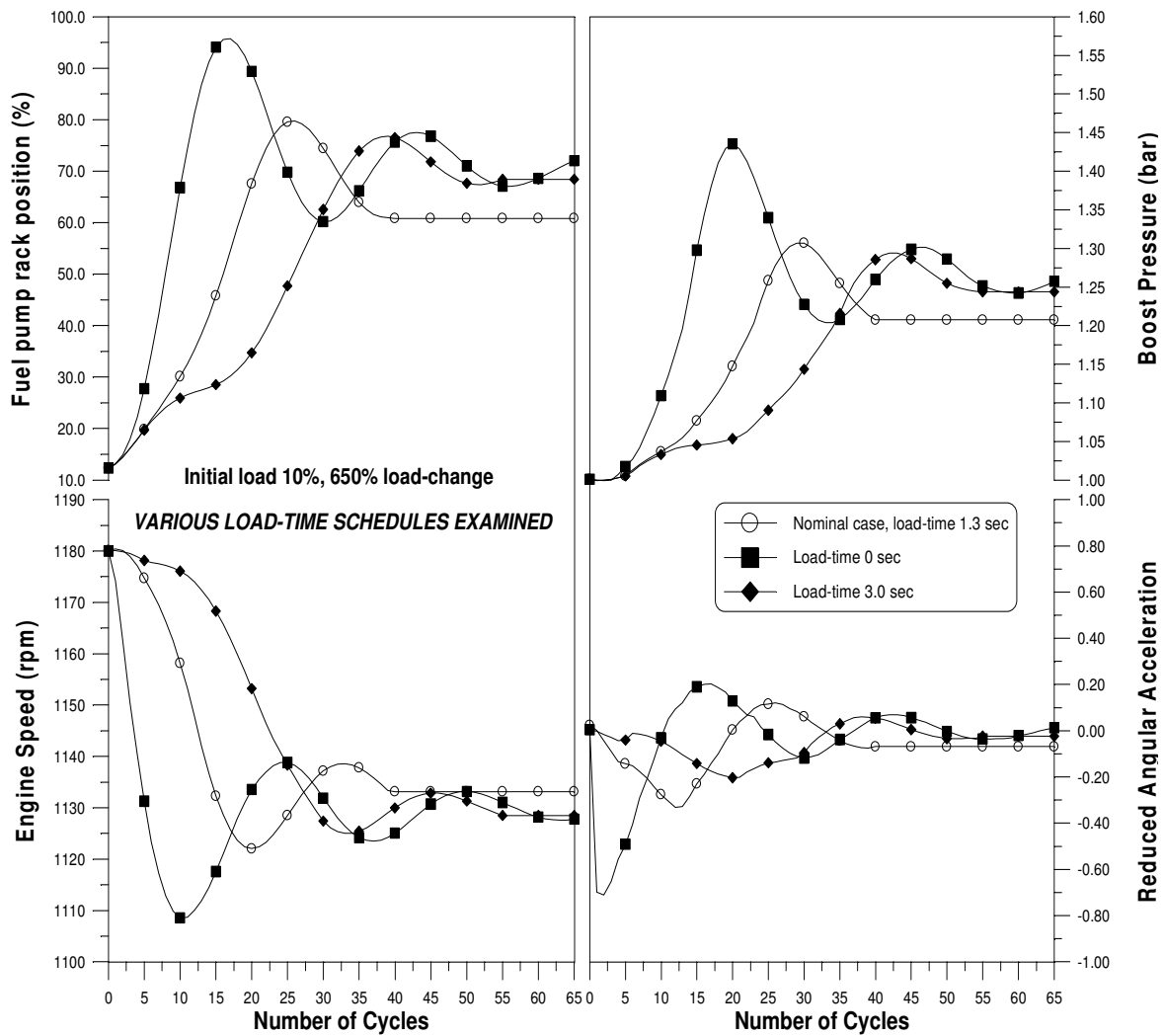

Figure 5. The effect of load-time schedule on the transient response. 


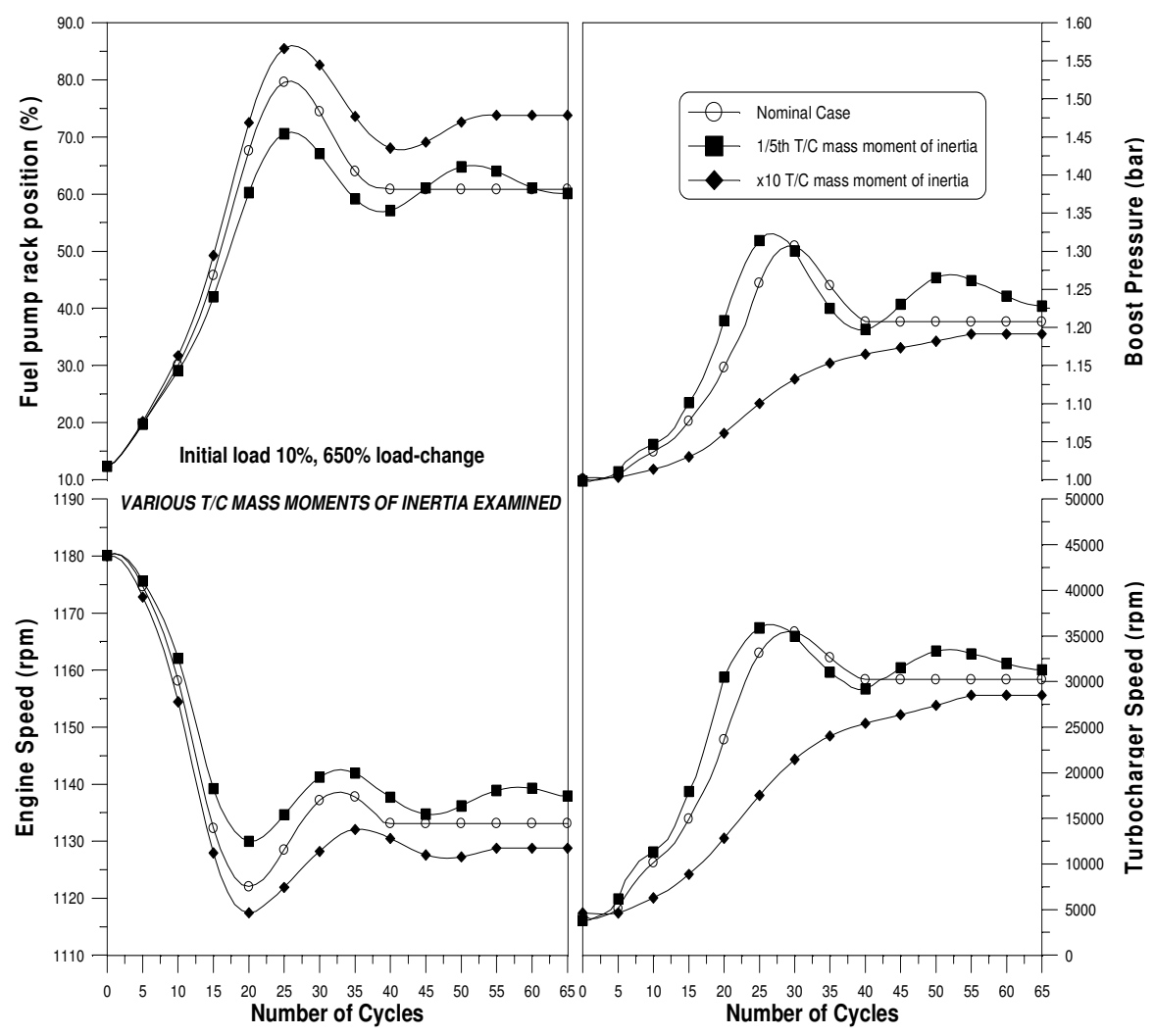

Figure 6 . The effect of turbocharger mass moment of inertia on the transient response.

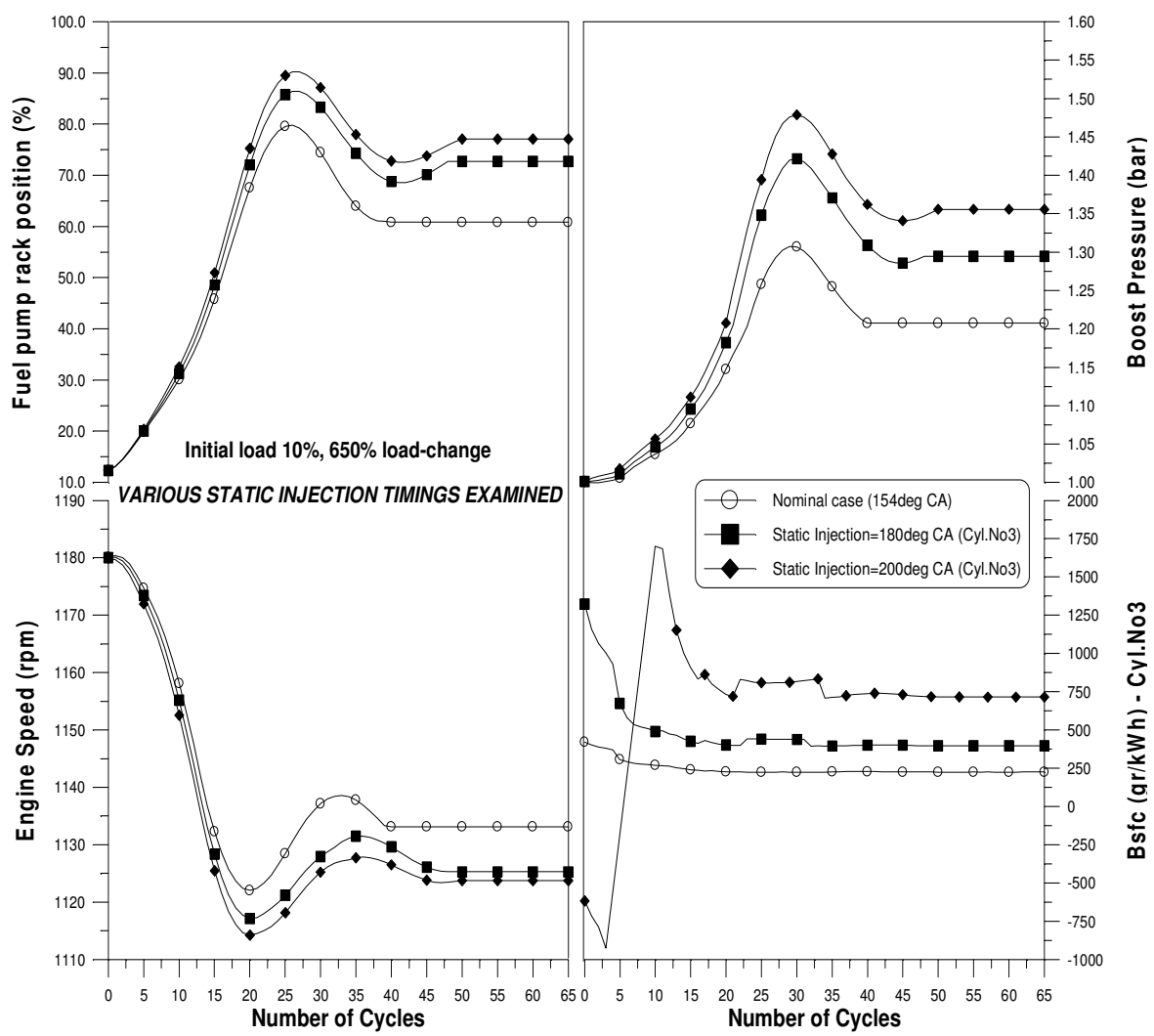

Figure 7. The effect of a malfunctioning fuel pump on the transient response. 


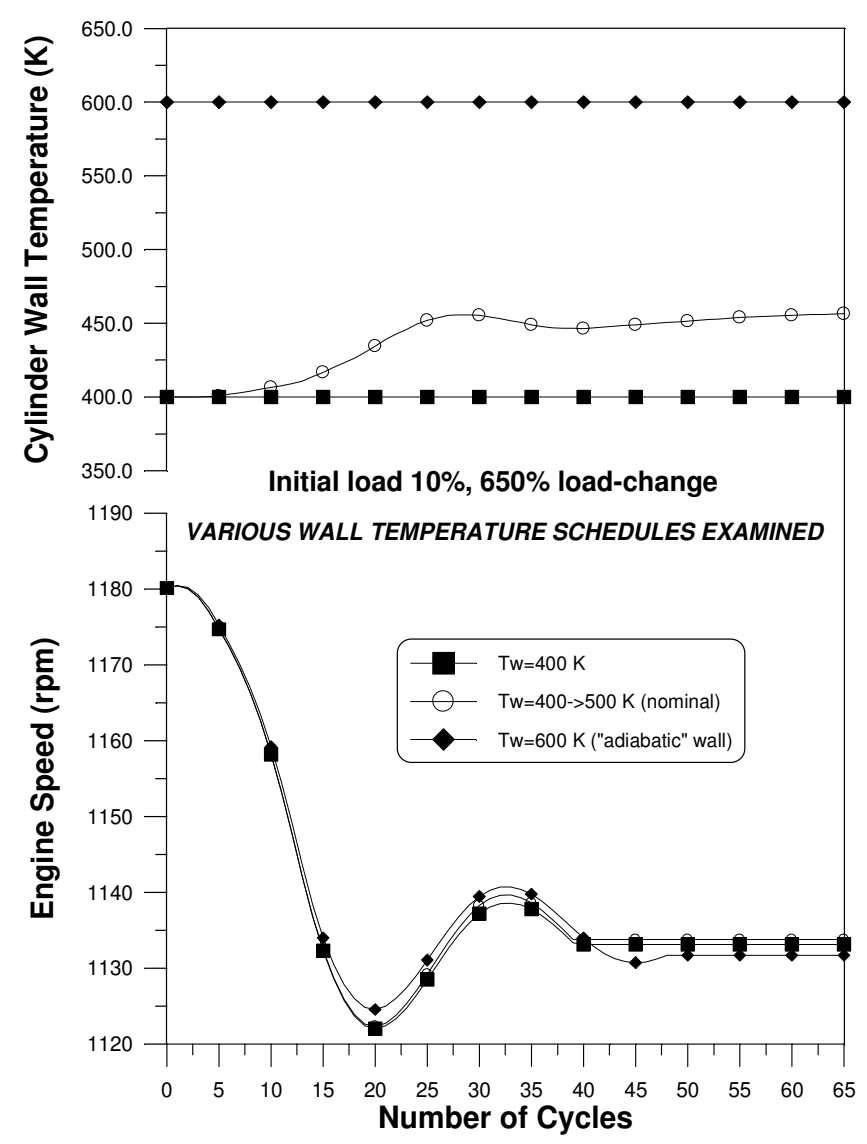

Figure 8. The effect of cylinder wall temperature on the transient response. in hand has indeed a twin entry turbine and its manifold consists of two parts, the single entry case was considered as the nominal one, since it is believed that a pressure-wave analysis in the exhaust manifold(s) is necessary for a thorough and reliable modelling of its thermodynamic condition.

Finally, the effect of the aftercooler effectiveness is depicted in Figure 11. It is clear that the particular parameter does not affect the dynamic response of the engine.

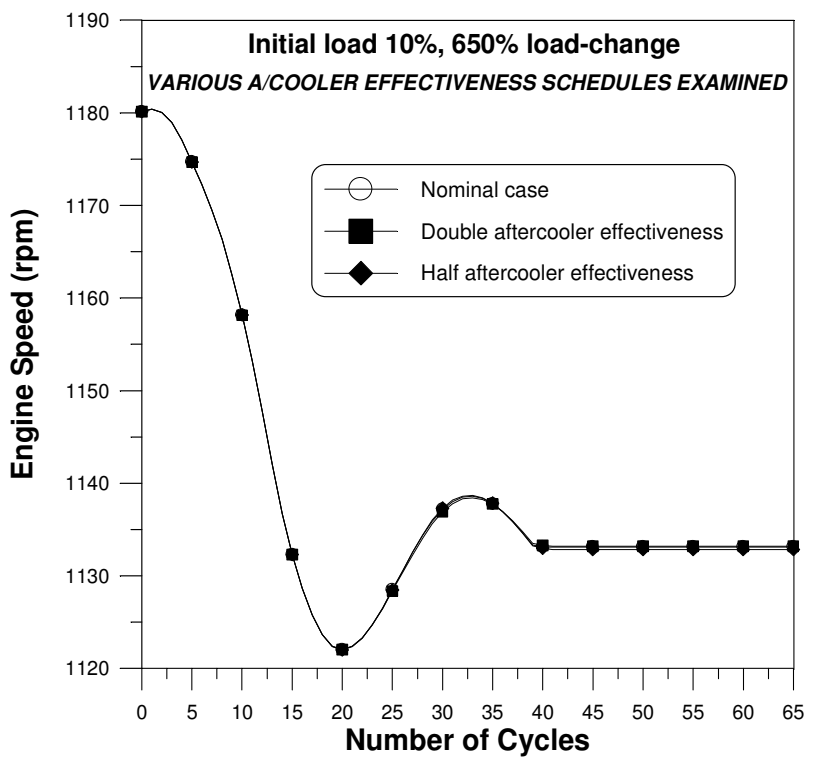

Figure 11. The effect of aftercooler effectiveness on the transient response.

\section{CONCLUSIONS}

A digital computer model was developed to study the transient performance of an IDI, turbocharged, multicylinder diesel engine operating under load changes. The model incorporates some important transient modelling features concerning combustion, heat transfer, dynamic analysis, mechanical friction and fuel pump operation, while it is capable of treating every cylinder individually during the transient event.

An engine test bed instrumentation connected to a highspeed data acquisition system was set up to investigate the model's predictive capabilities, under both steadystate and transient operations.

A detailed parametric study was conducted to investigate the effect of various dynamic, thermodynamic and design parameters on the transient response of the engine in hand: 1,2 and 3 and the second connected to cylinders 4,5 and 6 . The twin entry turbine case leads to faster boost pressure response due to the smaller volume of each one of the two "exhaust manifolds". Although the engine
Figure 10 investigates the effect of the exhaust manifold configuration. The cases examined are those of a single and a twin entry turbine; in the latter the exhaust manifold consists of two parts, the first connected to cylinders No 2 and 3 and the second connected to cylinders 4,5 


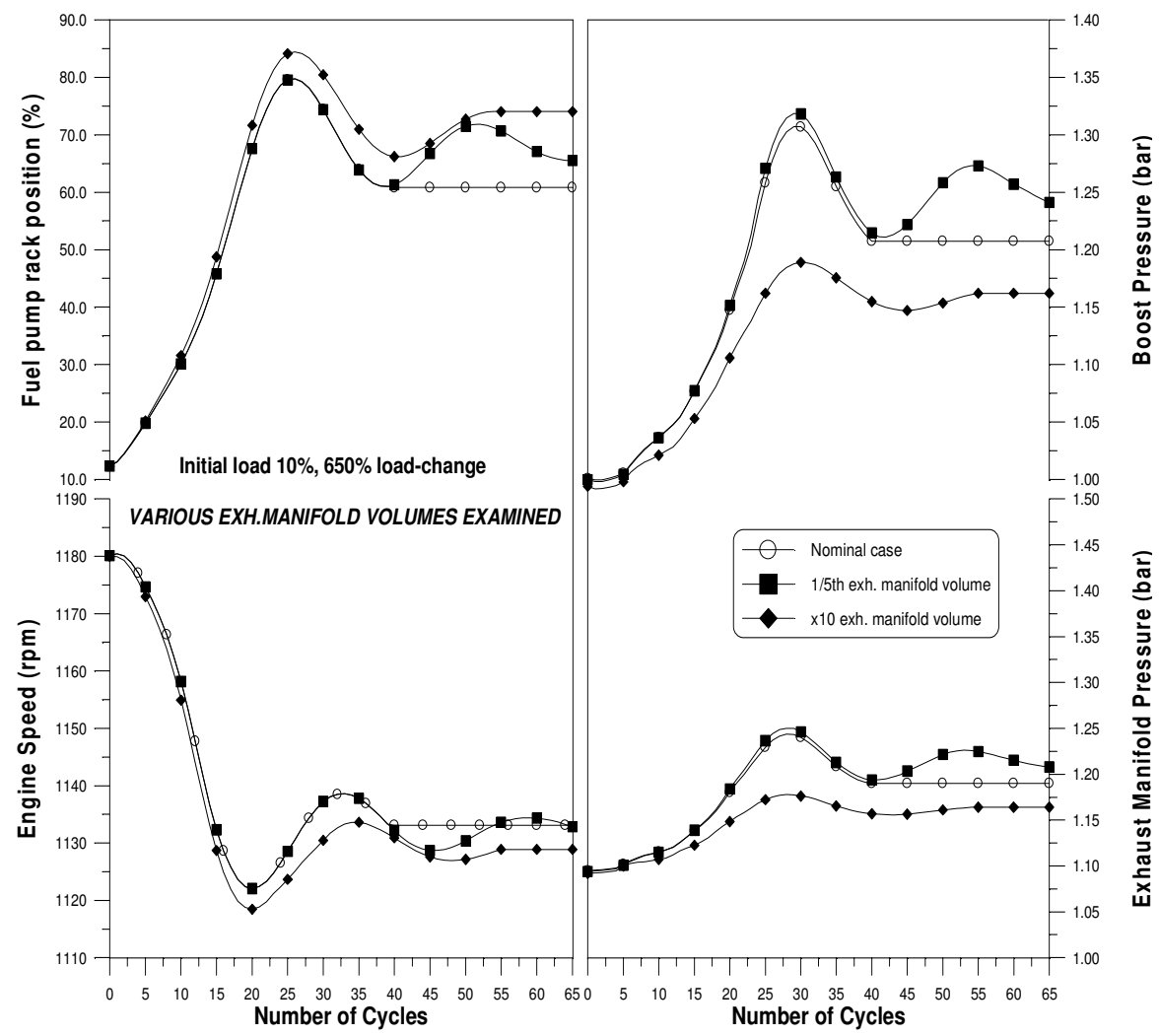

Figure 9. The effect of exhaust manifold volume on the transient response.

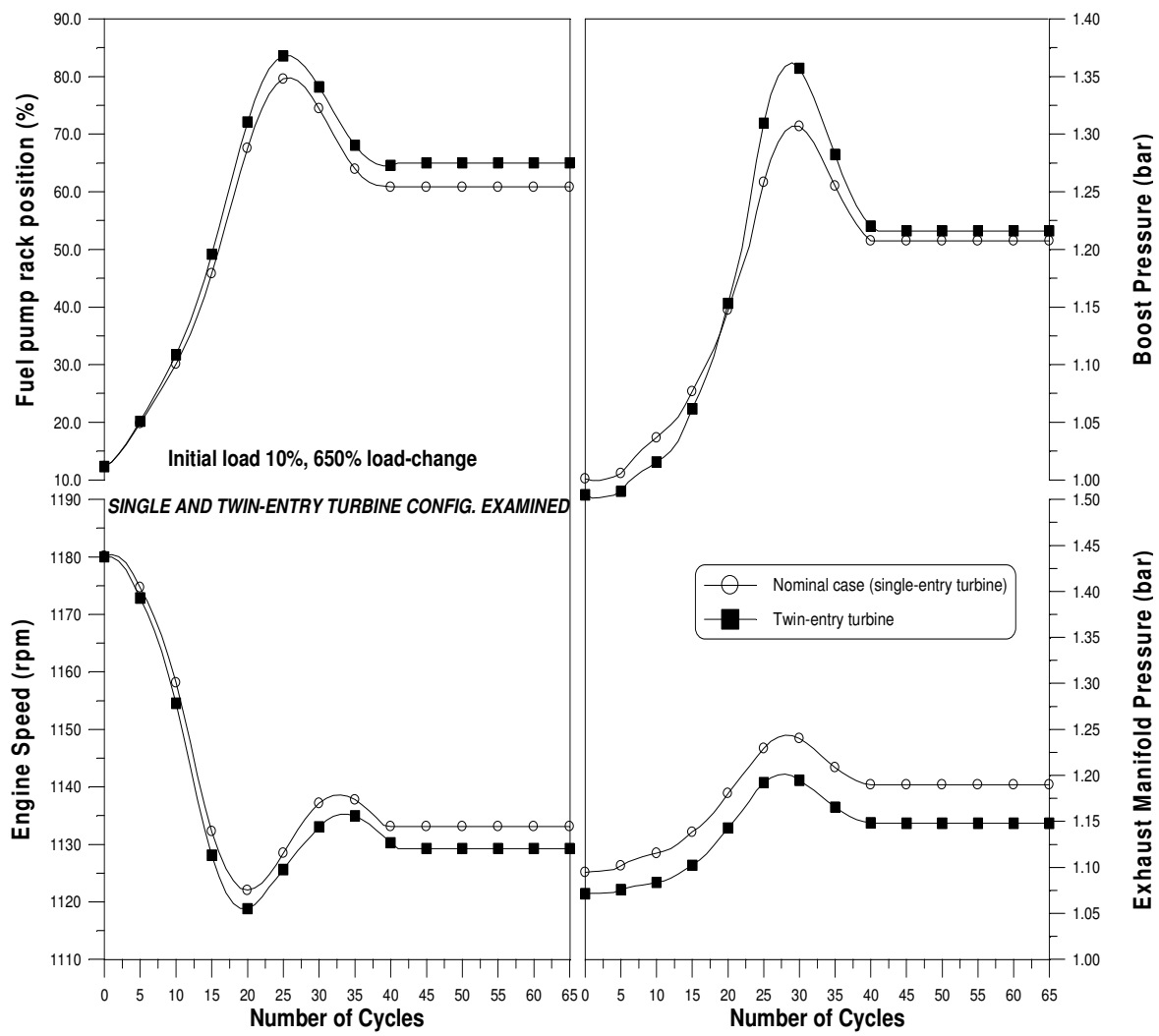

Figure 10. The effect of exhaust manifold configuration (single and twin-entry turbine) on the transient response. 
- The type of loading applied to the engine has a rather straightforward effect on the engine response. Under particular circumstances, e.g. $100 \%$ application of rigid loading, extreme situations, such as engine stall, may be experienced.

- The load-time schedule affects significantly the profile of the response but the final equilibrium conditions are more or less unaffected, while an instant load application can lead to pulsating recovery.

- A smaller turbocharger mass moment of inertia causes faster response but can lead to pulsating engine recovery.

- A delayed injection in even one of the six cylinders can cause significant increase in the speed droop.

- The effect of the cylinder wall temperature (profile) is shown to be minimal as regards engine equilibrium profile and final conditions.

- The effect of the aftercooler effectiveness in the engine transient response is similarly minimal.

- The exhaust manifold configuration can markedly affect the engine and turbocharger response after a ramp increase in load, leading even to unsteady and pulsating operation if a very small manifold volume is chosen.

It is strongly suspected that greater differences between the examined parameters exist, which could not be revealed due to the significantly high mass moment of inertia of the engine under study and its narrow speed range.

\section{REFERENCES}

1. Winterbone, D.E., Benson, R.S., Closs, G.D. and Mortimer, A.G., "A comparison between experimental and analytical transient test results for a turbocharged diesel engine", Proceedings of the Institution of Mechanical Engineers, Vol. 190, 267276, 1976.

2. Rackmil, C.I. and Blumberg, P.N., "Dynamic simulation of a turbocharged intercooled diesel engine with rack-actuated electronic fuel control system", SAE paper No 890394, 1989.

3. Watson, N. and Marzouk, M., "A non-linear digital simulation of turbocharged diesel engines under transient conditions", SAE paper No 770123, 1977.

4. Watson, N., "Transient performance simulation and analysis of turbocharged diesel engines", SAE paper No 810338, 1981.

5. Zellbeck, H. and Woschni, G., "Rechnerische Untersuchung des dynamischen Betriebs-verhaltens aufgeladener Dieselmotoren", Motor-Technische Zeitschrift (German), Vol. 44, 81-86, 1983.

6. Horlock, J.H. and Winterbone, D.E., "The Thermodynamics and Gas Dynamics of Internal Combustion Engines, Vol. II', Clarendon press, Oxford, 1986.

7. Qiao, J., Dent, J.C. and Garner, C.P., "Diesel engine modelling under steady and transient conditions using a transputer based concurrent computer", SAE paper No 922226, 1992.

8. Bazari, Z., "Diesel exhaust emissions prediction under transient operating conditions", SAE paper No 940666, 1994.

9. Murayama, T., Miyamoto, N., Tsuda, T., Suzuki, M. and Hasegawa, S., "Combustion behaviors under accelerating operation of an IDI diesel engine", SAE paper No 800966, 1980.

10. Winterbone, D.E. and Tennant, D.W.H., "The variation of friction and combustion rates during diesel engine transients", SAE paper No 810339, 1981.

11. Jiang, Q. and van Gerpen, J.H., "Prediction of diesel engine particulate emission during transient cycles", SAE paper No 920466, 1992.

12. Filipi, Z., Wang, Y. and Assanis, D., "Effect of variable geometry turbine (vgt) on diesel engine and vehicle system transient response", SAE paper No 2001-01-1247.

13. Arcoumanis, C., Megaritis, A. and Bazari, Z., "Analysis of transient exhaust emissions in a turbocharged vehicle diesel engine", Institution of Mechanical Engineers, Conference on Turbocharging and Turbochargers, London, U.K., Paper C484/038, pp. 71-81, 1994.

14. Assanis, D.N., Filipi, Z., Fiveland, S. and Syrimis, M., "A methodology for cycle-by-cycle transient heat release analysis in a turbocharged direct-injection diesel engine", SAE paper No 2000-01-1185.

15. Ciesla, C., Keribar, R. and Morel, T., "Engine/ powertrain/vehicle modeling tool applicable to all stages of the design process", SAE paper No 200001-0934.

16. Rakopoulos, C.D. and Giakoumis, E.G., "Simulation and analysis of a naturally aspirated, indirect injection diesel engine under transient conditions comprising the effect of various dynamic and thermodynamic parameters", Energy Conversion and Management, Vol. 39, pp. 465-484, 1998.

17. Rakopoulos, C.D., Giakoumis, E.G. and Hountalas, D.T., "A simulation analysis of the effect of governor technical characteristics and type on the transient performance of a naturally aspirated IDI diesel engine", SAE paper No 970633, SAE Transactions, Journal of Engines, Vol. 106, pp. 905-922, 1997.

18. Rakopoulos, C.D., Giakoumis, E.G. and Hountalas, D.T., "Experimental and simulation analysis of the transient operation of a turbocharged multi-cylinder IDI diesel engine", Energy Research, Vol. 22, pp. 317-332, 1998.

19. Benson, R.S. and Whitehouse, N.D., "Internal Combustion Engines", Pergamon press, Oxford, 1979.

20. Heywood, J.B., "Internal Combustion Engine Fundamentals", McGraw-Hill, New York, 1988.

21. Rakopoulos, C.D. and Hountalas, D.T., "Development and validation of a 3-D multi-zone combustion model for the prediction of DI diesel engines performance and pollutants emissions", SAE 
paper No 981021, SAE Transactions, Journal of Engines, Vol. 107, pp. 1413-29, 1998.

22. Rakopoulos, C.D. and Hountalas, D.T., "Development of new 3-D multi-zone combustion model for indirect injection diesel engines with a swirl type prechamber", SAE paper No 2000-01-0587, SAE Transactions, Journal of Engines, Vol. 109, pp.718-733, 2000.

23. Rakopoulos, C.D. and Giakoumis, E.G., "Simulation and exergy analysis of transient diesel engine operation", Energy, Vol. 22, pp. 875-886, 1997.

24. Whitehouse, N.D. and Way, R.G.B., "Rate of heat release in diesel engines and its correlation with fuel injection data", Proceedings of the Institution of Mechanical Engineers, Vol. 184, Part 3J, pp. 17-27, 1969-70.

25. Hiroyasu, H., Kadota, T. and Arai, M., "Development and use of a spray combustion modelling to predict diesel engine efficiency and pollutant emissions", Bulletin JSME, Vol. 26, pp. 569-76, 1983.

26. Annand, W.J.D., "Heat transfer in the cylinders of reciprocating internal combustion engines", Proceedings of the Institution of Mechanical Engineers, Vol. 177, pp. 983-990, 1963.

27. Rezeka, S.F. and Henein, N.A., "A new approach to evaluate instantaneous friction and its components in internal combustion engines", SAE paper No 840179, 1984.

28. Rakopoulos, C.D., Hountalas, D.T., Koutroubousis, A.P. and Zannis, T.C., "Application and evaluation of a detailed friction model on a DI diesel engine with extremely high peak combustion pressures", SAE paper No 2002-01-0068, SAE Transactions, Journal of Engines, Vol. 111, pp. 308-321, 2002.

29. Kouremenos, D.A., Rakopoulos, C.D., Hountalas, D.T. and Kotsiopoulos, P.N., "A simulation technique for the fuel injection system of diesel engines", ASME-Winter Annual Meeting, Atlanta, Georgia, Proc. Advanced Energy Systems, Vol. 24, pp. 91102, 1991.

30. Watson, N. and Janota, M.S., "Turbocharging the Internal Combustion Engine", MacMillan, London, 1982.

\section{NOMENCLATURE}

$\begin{array}{ll}\text { a,b,c: } & \text { constants } \\ \mathrm{C}_{\mathrm{p}}: & \text { piston speed, } \mathrm{m} / \mathrm{s} \\ \mathrm{G}: & \text { mass moment of inertia, } \mathrm{kg} \mathrm{m}^{2} \\ \mathrm{k}: & \text { load torque constant } \\ \mathrm{N}: & \text { engine speed, } \mathrm{rpm} \\ \mathrm{p}: & \text { pressure, bar } \\ \mathrm{r}: & \text { crank radius, } \mathrm{m} \\ \mathrm{T}: & \text { temperature, } \mathrm{K}, \text { or torque, } \mathrm{N} \mathrm{m} \\ \mathrm{t}: & \text { time, } \mathrm{s} \\ \mathrm{V}: & \text { volume, } \mathrm{m}^{3} \\ \mathrm{z}: & \text { fuel pump rack position, } \mathrm{m}\end{array}$

\section{Greek}

$\varepsilon$ : angular acceleration, $\mathrm{s}^{-2}$, or aftercooler effectiveness

$\lambda: \quad$ ratio of crank radius to connecting rod length

$\varphi: \quad$ crank angle, deg. from the TDC position

$\omega: \quad$ angular velocity, $\mathrm{s}^{-1}$

\section{Subscripts}

$\begin{array}{ll}\text { ac: } & \text { aftercooler } \\ \mathrm{C}: & \text { compressor } \\ \mathrm{e}: & \text { engine } \\ \mathrm{fr}: & \text { friction } \\ \mathrm{i}: & \text { injected } \\ \mathrm{L}: & \text { load } \\ \mathrm{m}: & \text { mechanical } \\ \mathrm{O}: & \text { initial conditions } \\ \mathrm{O}: & \text { oxygen } \\ \text { st: } & \text { steady-state } \\ \mathrm{T}: & \text { turbine } \\ \mathrm{TC}: & \text { turbocharger } \\ \text { trans: } & \text { transient } \\ \mathrm{u}: & \text { unprepared (fuel) } \\ \text { w: } & \text { wall }\end{array}$

\section{Superscripts}

o: nominal conditions

st: $\quad$ steady-state

\section{Abbreviations}

${ }^{\circ} \mathrm{CA}$ : degrees crank angle

BDC: bottom dead centre

bmep: brake mean effective pressure, bar

IDI: indirect injection

rpm: revolutions per minute

SMD: $\quad$ Sauter mean diameter, $\mu \mathrm{m}$

TDC: $\quad$ top dead centre 